\title{
Histological Evaluation of the Effect of Local Application of Grape Seed Oil on Healing Process of Extracted Tooth Socket in Rabbits
}

Manar Abd Alrazaq Hassan (BDS, MSc) ${ }^{1}$ and Nada MH AL-Ghaban (BDS, MSc, $\mathrm{PhD})^{2}$

\begin{abstract}
\end{abstract}
Background: The process of wound healing in the socket include the healing of wounds in soft tissues, and healing of the bone. The herbal medicament widely used in the healing of different wounds. The benefit of Grape seed oil due to their anti-oxidant and antiinflammatory effect.

Objective: Histological evaluation the effects of local application of grape seeds oil in the healing process of dental socket after tooth extraction and compared the res ult with normal healing process.

Patients and Methods: Thirty six New Zeland male rabbits were used in this study, the upper right central incisor was extracted for each rabbit, then the rabbits were divided into 3 main groups ;Control group: 12 rabbits , the socket heal spontaneously , sponge group:12 rabbits ,the socket treated with absorbable hemostatic sponge and grape seed oil group: 12 rabbits, the socket treated with local application of $0.5 \mathrm{ml} / \mathrm{Kg}$ of $\mathrm{B}$.W. grape seeds oil fixed by absorbable hemostatic sponge. Then each group were divided into two sub group according to the healing intervals 2 and 4 week (6 rabbits from each group). Histological evaluation performed by section stained with hematoxylin and eosin (H\&E), and histomorphometric analysis for assessment of osteoclasts ,osteoblasts, osteocytes, trabecular no., trabecular area and marrow space area by Image J. software.

Results: The histological and histomorphometric results of present study showed enhancement of healing process in grape seeds oil and sponge group after tooth extraction by activation of large number of osteoblasts, osteocytes and osteoclasts that started from apical part, then middle part finally in coronal part of the socket.

Conclusion: Grape seed oil accelerate the healing process after locally treated tooth socket and assessed in new bone formation.

Keywords: Grape seed oil, Absorbable hemostatic sponge, Bone healing.

Corresponding Author: manar.histo@gmail.com

Received: $15^{\text {th }}$ May 2019

Accepted: $2^{\text {nd }}$ June 2019

DOI:https://doi.org/10.26505/DJM.17024670515

${ }^{1}$ College of Medicine- Diyala University-Diyala-Iraq.

${ }^{2}$ Department of Oral Diagnosis- College of Dentistry-University of Baghdad- Baghdad- Iraq 


\section{Introduction}

Alveolar process of the bone of jaws, that contain socket for supporting the teeth. The alveolar process was divided into two parts[1] :

A: Alveolar bone proper: It's contains perforating fibers "Sharpeys". These collagen fibers perforate alveolar bone proper at oblique or right angle to the long axis of the tooth surface.

B: Supporting alveolar bone: It'was the bone that surrounds the alveolar bone proper and provided support to the dental socket. It's comprises of two parts: Cortical plate and Spongy bone [2].

Bone Healing : the healing process was involves "an inflammatory phase, a reparative phase and then a final remodeling phase" [3]; [4] .The inflammatory phase comprises of "a hematoma formation, immune response and progenitor cell recruitment to the socket". The reparative phase comprises of "revascularization and bone formation by both intramembranous and endochondral pathways" [5]. Finally remodeling process to refurbish and restore the normal bone structure. Sites that were mechanically and naturally stable may predominantly heal with primary bone in an "intramembranous pathway"[4]. Grape seeds oil: Plant origin :seeds of Vitis Vinifera L, is made by "cold-pressing the grape seeds". It has been broadly used in the world. It contains minerals, vitamins, lipids, proteins, antioxidants and carbohydrates [6].

Grape seed oil contains high concentration of linoleic acid, vitamin E, oligomeric proanthocyanidin complexes "OPCs" (about
95\%) and contained phenolic compounds such as phenolic acids, flavonoids and antioxidants [7]. Proanthocyanidins were a groups of polyphenyl phenolic bioflavonoids that biologically active, produced by many plants. The proanthocyanidin specifically in grape seed can induce VEGF production in human keratinocytes [8].

Plant proanthocyanidins were known as the functional food factors that keep a variety of physiological activities such as antimicrobial, antioxidant, anti-caries, anti-allergy, chemopreventive effects [9], antihypertensive and inhibition the activities of many physiological enzymes and its receptors [10]. The greater part of these activities of largely depends on their degree of polymerization and its structures. Grape seed contains high amounts of these polyphenols [11], [12].

"Absorbable Hemostatic Gelatin Sponges" are sterilized, absorbable gelatin porcine sponges used for hemostasis, by applying in to a bleeding site and not applied in contaminated body areas. They are off-white color and porous in appearance. The sponge Hemostasis the bleeding in $(2-4)$ minutes, Liquefies in (2-5)days in contact with mucosa, and it was absorbs at least 35 times its own weight in fluids and blood [13].

\section{Patients and Methods}

All experimental procedures were carried out in accordance with the ethical principles of animal experimentation of College of Dentistry, University of Baghdad. The animals were kept under nursing and supervision from the staff of the animal house, College of Medicine, Diyala 
University for about 3 months started from September, 2018 and end in January 2019.

For each rabbits (36) used in this study, aged between $6-8$ months[14], their weight ranged between " $1-1.5 \mathrm{~kg}$ ", tooth were extracted after general anesthesia. Then the rabbits were divided randomly into 3 main groups "one control and two experimental groups" :-

1- Control group (C) (12 rabbits):- The socket heal spontaneously after tooth extraction.

2- Sponge group $(\mathrm{S})$ ( (12 rabbits):- The socket treated with absorbable hemostatic sponge $\left(0.5^{*} 0.5^{*} 1 \mathrm{~cm}\right)$ after tooth extraction .

3- Grape seed oil and sponge group (GS)(12 rabbits):- The socket treated with combined the absorbable hemostatic sponge with local application of $0.5 \mathrm{ml} / \mathrm{Kg} \mathrm{BW}$ grape seeds oil after tooth extraction.

Then each group was divided into two sub groups according to the time of scarification 2 and 4 weeks after tooth extraction (6 rabbit from from each group). At the end of each interval, the animals were sacrificed and the specimens were prepared for histological (H\&E)stain. The histomorphometric examination was done by dividing the microscopical fields of each tooth socket into 3 parts. "coronal, middle and apical parts" [15], counting the number of osteoblasts, osteocytes, and osteoclast in each part of the socket of the histological section (H\&E stain) in each group at 2 and 4 weeks healing interval. The bone cells counting done at $40 \mathrm{X}$ magnification [16] [17]. The most classical histomorphometric parameters, used for the explanation of bone micro architecture (Trabecular area, Trabecular number and Bone marrow area), based on mathematical morphology It was calculated at by " Image J. exe" software program.

\section{Statistical analysis}

Statistical analyses were calculated by descriptive data analysis and inferential data analysis( ANOVA and LSD test) in all comparison significant $\mathrm{P}$ - value was ( $\mathrm{P}<0.05)$.

\section{Results}

\section{I- 2 week durations}

\section{A- Histological findings for Control group}

Coronal, middle and apical area of the socket showed new trabecular bone originated from socket bone, and surrounded by osteoblasts and osteoclasts, in addition to formation of number of osteocytes and numerous blood vessels Figure $(1,2,3$.) 


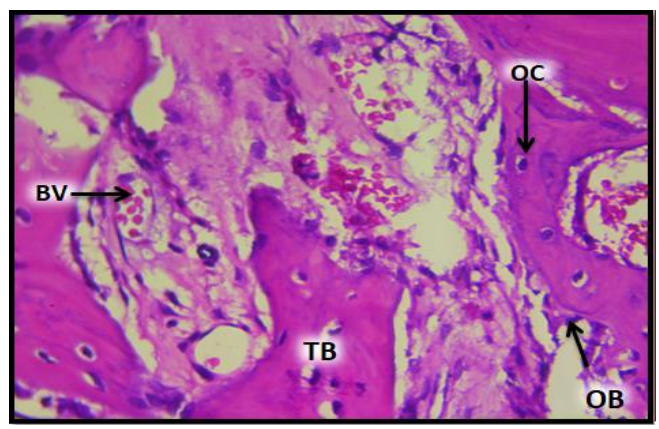

Figure(1): Photomicrograph showing the coronal part of 2 weeks in C group( H\&E X40)

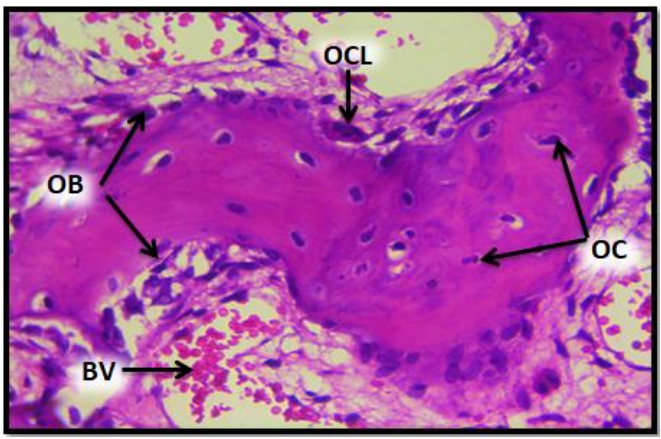

Figure (2): Photomicrograph showing the middle part of the $\mathrm{C}$ group at 2 weeks (H \&E X40)

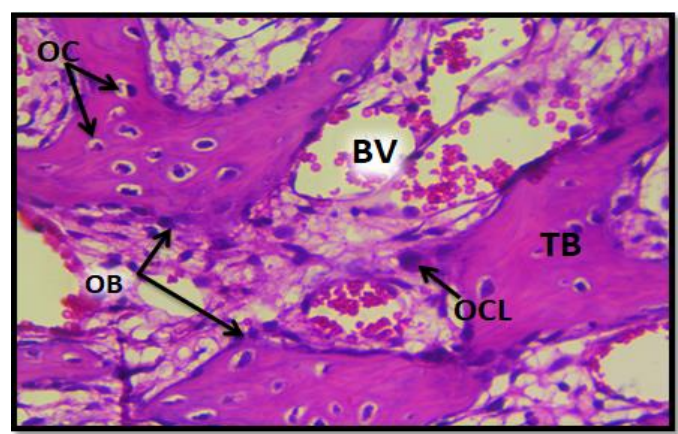

Figure (3) :Photomicrograph showing the apical part of the C group at 2 weeks (H \&E X40)

\section{B-Histological findings for Sponge group:}

Coronal, middle and apical area of the socket :- showed new trabecular bone formation, surrounded by osteoblasts and presence of osteoclasts and covered by fibrous connective tissue on the surface of the socket and presence of new blood vessels Figure $(4,5,6)$. 


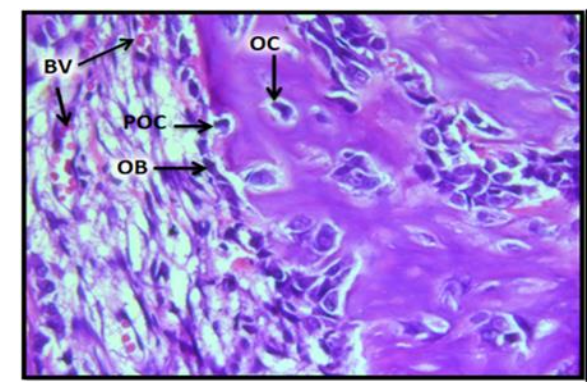

Figure (4): Photomicrograph showing the coronal part of S group in 2 weeks. (H\&E X40)

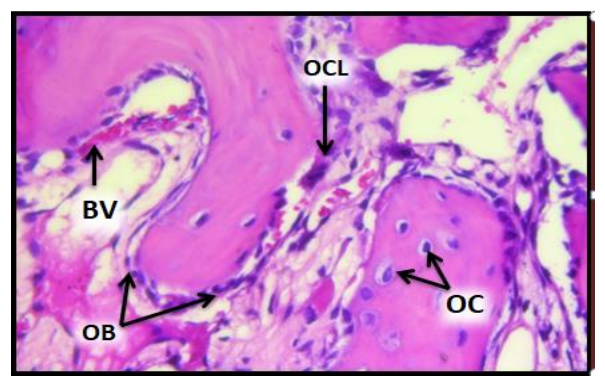

Figure (5): Photomicrograph showing the middle part of S group at 2 weeks (H\&E X40)

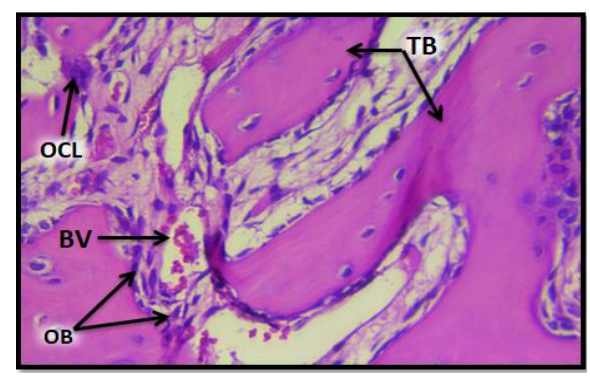

Figure (6): Photomicrograph showing the apical part of S group at 2 weeks ( H\&E X40)

\section{C-Histological findings for grape seed oil and sponge group}

Coronal, middle and apical area of the socket showed new trabecular bone formation lined by high number of osteoblasts, osteoclasts formation, and contain numerous osteocytes and blood vessels Figure $(7,8,9)$. 


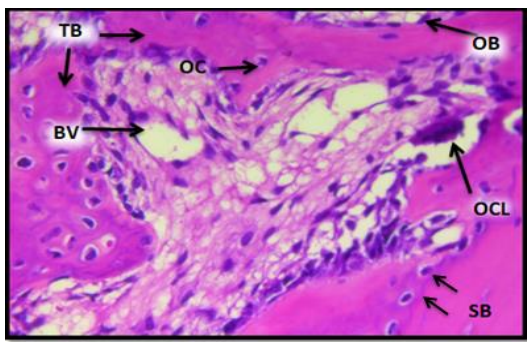

Figure (7): Photomicrograph showing the coronal part of GS group at 2 weeks ( H\&E X40)

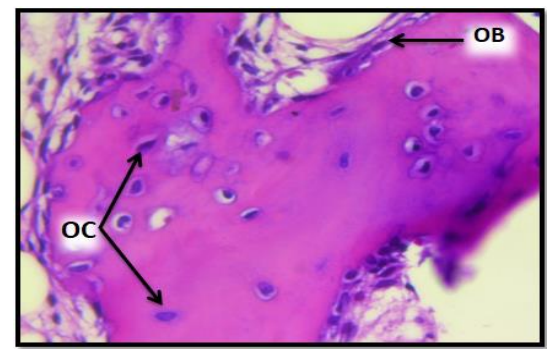

Figure (8): Photomicrograph showing the middle part of GS group at 2 weeks (H\&E X40)

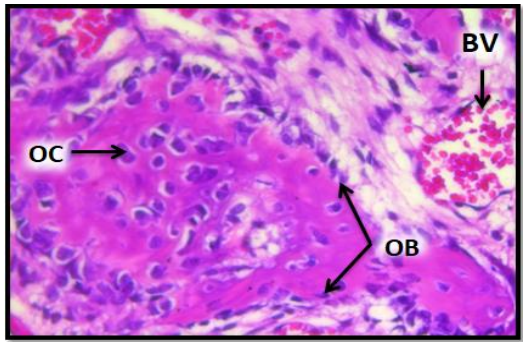

Figure (9): Photomicrograph showing the apical part of GS group at 2 weeks ( H\&E X40)

\section{I- 4 Weeks durations}

\section{A- Histological findings for Control}

group: Coronal, middle and apical area of the socket showed the fibrous connective tissue cover the socket with thick trabecular bone and filled with osteocytes and osteoblasts lined the surface of new bone with numerous new blood vessels Figure $(10,11,12)$.

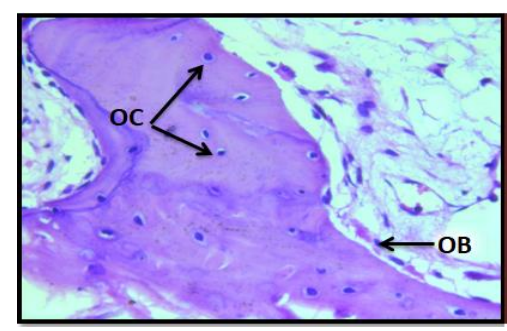

Figure (10): Photomicrograph showing the coronal part of $C$ group at 4 weeks (H\&E X40) 


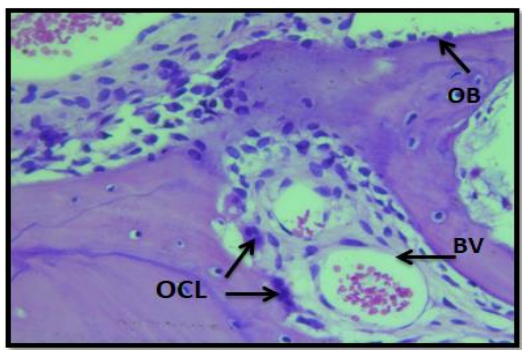

Figure (11): Photomicrograph showing the middle part of C group at 4 weeks (H\&EX40)

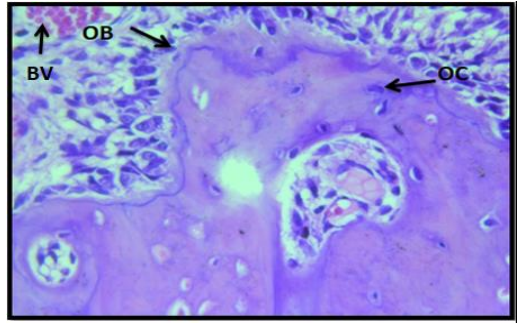

Figure (12) :Photomicrograph showing the apical part of C group at 4 weeks (H\&E X40).

\section{B-Histological findings for sponge group socket portion with layer of fibrous} Coronal, middle and apical area of the socket connective tissue, with high number of blood showed tissue new trabecular bone filled the vessels and fat cells Figure $(13,14,15)$.

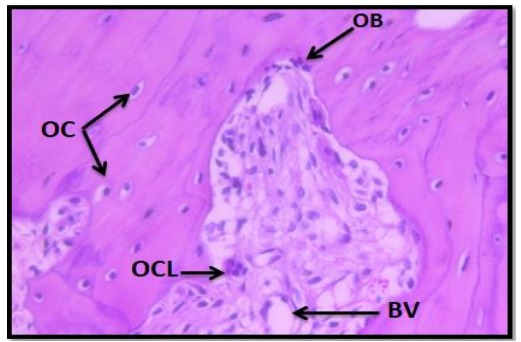

Figure (13) : Photomicrograph showing the coronal part of S group at 4 weeks (H \&E X40)

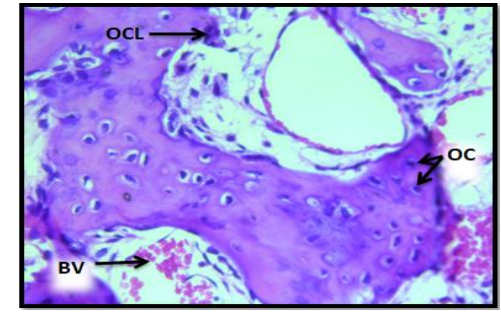

Figure (14): Photomicrograph showing the middle part of $S$ group at 4 weeks (H \&E X40)

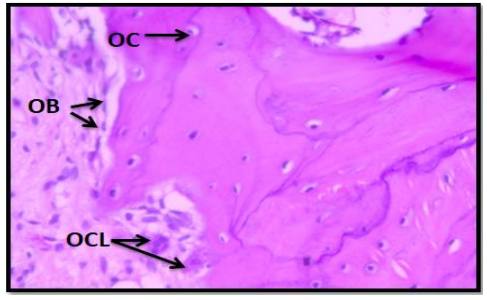

Figure (15) : Photomicrograph showing the apical part of $\mathrm{S}$ group at 4 weeks (H \&E X40) 
C-Histological findings for grape seed oil and sponge group :- Coronal, middle area of the socket :- showed the mature thick bone trabeculae separated from socket bone by reversal line with osteocyte in new bone arranged in haversian system around haversian cana contain high number of osteocytes and lined by single layer of osteoblasts Figure $(16,17,18)$.

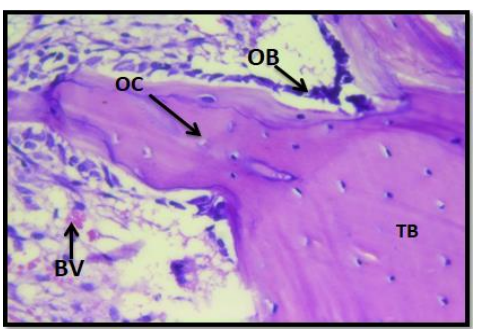

Figure (16) :Photomicrograph showing the coronal part of GS at 4 weeks group (H \&EX40)

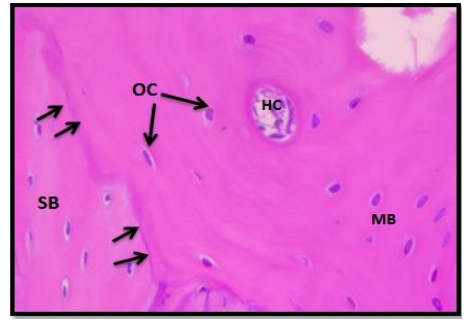

Figure (17): Photomicrograph showing the middle part of the GS group at 4 weeks (H \&E 40\%).

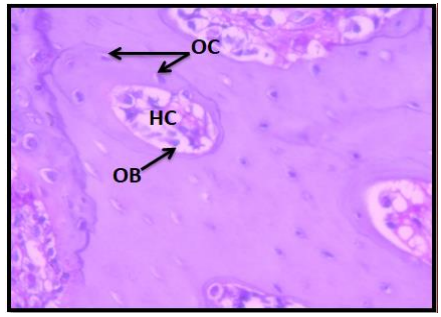

Figure (18) : Photomicrograph showing the apical part of GS group at 4 weeks (H \&E X40)

\section{II- Statistical analysis}

A-Descriptive data analysis1-Descriptive data analysis for bone cell in the study groups at different periods:- Table (1) showed The osteoblast number, osteocyte number, recorded higher mean value in GS group than other groups in all area of the socket Furthermore, the higher mean value for osteoclasts in all groups seen in the all area of the socket in $\mathrm{C}$ group at 2 weeks and 4 weeks duration. 
Table (1): Descriptive statistic of the bone cells in each area of the socket for each healing periods

\begin{tabular}{|c|c|c|c|c|c|c|c|c|}
\hline \multirow{2}{*}{ Area } & \multirow{2}{*}{ Week } & \multirow{2}{*}{ Group } & \multicolumn{2}{|c|}{$\mathrm{OB}$} & \multicolumn{2}{|c|}{$\mathrm{OC}$} & \multicolumn{2}{|c|}{ OCL } \\
\hline & & & Mean & S. D. & Mean & S. D. & Mean & S.D. \\
\hline \multirow{3}{*}{ Coronal } & \multirow{3}{*}{2 Weeks } & C group & 777.0 & 8.51 & $\begin{array}{ll}17.8 \\
\end{array}$ & 3.56 & 2.0 & 1.22 \\
\hline & & S group & 66.2 & 5.40 & 18.8 & 5.40 & 1.2 & .83 \\
\hline & & GS group & 85.8 & 5.40 & 32.6 & 7.95 & 1.4 & .89 \\
\hline \multirow{3}{*}{ Coronal } & \multirow{3}{*}{4 Weeks } & C group & 31.8 & 7.69 & 31.0 & 5.95 & 1.0 & .70 \\
\hline & & S group & 38.4 & 5.81 & 32.6 & 9.73 & . .8 & .83 \\
\hline & & GS group & 30.8 & 10.84 & 37.8 & 4.86 & .6 & .54 \\
\hline \multirow{3}{*}{ Middle } & \multirow{3}{*}{2 Weeks } & $\mathrm{C}$ group & 83.0 & 8.15 & 27.4 & 2.79 & 2.2 & .44 \\
\hline & & S group & 78.8 & 11.25 & 22.4 & 4.77 & 1.4 & 1.14 \\
\hline & & GS group & 86.2 & 4.65 & 35.4 & 4.15 & 1.0 & 0.00 \\
\hline \multirow{3}{*}{ Middle } & \multirow{3}{*}{4 Weeks } & C group & 40.2 & 4.65 & 34.8 & 6.57 & 1.0 & 1.22 \\
\hline & & S group & 33.0 & $\begin{array}{l}7.51 \\
\end{array}$ & $\begin{array}{l}40.4 \\
\end{array}$ & 10.23 & .8 & 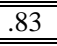 \\
\hline & & GS group & 28.6 & 2.70 & 39.0 & 4.18 & .8 & .44 \\
\hline \multirow{3}{*}{ Apical } & \multirow{3}{*}{2 Weeks } & C group & 90.2 & 8.67 & 36.2 & 10.84 & 2.2 & .83 \\
\hline & & S group & 86.4 & 3.28 & 24.0 & 6.40 & 1.4 & .54 \\
\hline & & GS group & 90.6 & 8.82 & 33.2 & 10.42 & 1.4 & .89 \\
\hline \multirow{3}{*}{ Apical } & \multirow{3}{*}{4 Weeks } & C group & 35.2 & 13.16 & $\begin{array}{l}40.4 \\
\end{array}$ & 15.46 & .6 & . .54 \\
\hline & & S group & 30.2 & 4.96 & 45.4 & 6.26 & $\bar{~} .6$ & .54 \\
\hline & & GS group & 20.2 & 8.22 & $\begin{array}{l}42.0 \\
\end{array}$ & "6.78 & 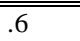 & .54 \\
\hline
\end{tabular}

2-Descriptive data analysis for Trabecular than the other groups in $2 \& 4$ weeks duration number, trabecular area and bone marrow and in all area of the socket. On the other space area in the study groups at different hand Bone marrow space area, the $\mathrm{C}$ group periods:Table (2) showed the mean of recorded the higher mean value than other trabecular number and trabecular area groups in both duration ( $2 \& 4$ weeks) and in recorded higher mean value in the GS group all socket area.

Table (2): Descriptive statistic of the Trabecular number, trabecular area, and bone marrow space area in each area of the socket for each healing periods

\begin{tabular}{|c|c|c|c|c|c|c|c|c|}
\hline \multirow{2}{*}{ Area } & \multirow{2}{*}{ Week } & \multirow{2}{*}{ Group } & \multicolumn{2}{|c|}{ T. NO } & \multicolumn{2}{|c|}{ T. AR } & \multicolumn{2}{|c|}{ BM. AR } \\
\hline & & & Mean & S. D. & Mean & S. D. & Mean & S. D. \\
\hline \multirow{3}{*}{ Coronal } & \multirow{3}{*}{2 Weeks } & C group & 17.0 & 4.47 & $\begin{array}{c}1.061 \\
\end{array}$ & .58 & 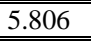 & 1.83 \\
\hline & & S group & 16.0 & 2.54 & 2.641 & 2.92 & 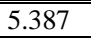 & 2.38 \\
\hline & & GS group & 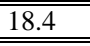 & 1.94 & $\begin{array}{c}3.507 \\
\end{array}$ & $\begin{array}{ll}1.60 \\
\end{array}$ & 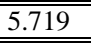 & 1.74 \\
\hline \multirow{3}{*}{ Coronal } & \multirow{3}{*}{4 Weeks } & C group & 7.8 & 2.58 & 5.015 & 2.27 & 2.941 & .53 \\
\hline & & S group & 6.6 & 1.51 & 6.285 & .89 & 2.211 & .86 \\
\hline & & GS group & 7.4 & 2.50 & 7.983 & 1.05 & 2.685 & 1.55 \\
\hline \multirow{3}{*}{ Middle } & \multirow{3}{*}{2 Weeks } & C $\mathrm{Croup}$ & 18.2 & 3.34 & 3.616 & 1.61 & $\begin{array}{l}5.157 \\
\end{array}$ & 1.00 \\
\hline & & S group & 17.2 & 4.14 & 3.095 & 2.38 & 5.003 & 1.30 \\
\hline & & GS group & 17.0 & 4.69 & 4.164 & .90 & $\begin{array}{l}5.188 \\
\end{array}$ & 2.42 \\
\hline \multirow{3}{*}{ Middle } & \multirow{3}{*}{4 Weeks } & C group & 6.0 & $\begin{array}{l}1.00 \\
\end{array}$ & 6.366 & 3.47 & 2.671 & 1.17 \\
\hline & & S group & 6.4 & .89 & 7.143 & 1.28 & 2.069 & .58 \\
\hline & & GS group & 6.6 & 1.14 & 8.639 & 1.16 & 2.466 & 1.82 \\
\hline \multirow{3}{*}{ Apical } & \multirow{3}{*}{2 Weeks } & C group & 23.4 & 7.63 & 4.019 & 1.52 & 4.012 & 2.29 \\
\hline & & S group & 17.6 & 3.71 & 4.275 & .69 & 5.095 & 1.25 \\
\hline & & GS group & 17.2 & 1.30 & 5.019 & 1.04 & 3.769 & 2.84 \\
\hline \multirow{3}{*}{ Apical } & \multirow{3}{*}{4 Weeks } & C group & 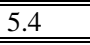 & 1.34 & 7.210 & 1.86 & 2.357 & 2.80 \\
\hline & & S group & 5.4 & 1.14 & 8.185 & 1.165 & 1.626 & .42 \\
\hline & & GS group & $\begin{array}{c}5.4 \\
\end{array}$ & 1.51 & 10.059 & 2.14 & 1.822 & .84 \\
\hline
\end{tabular}


Histological Evaluation of the Effect of Local Application of Grape Seed Oil on Healing Process of

\section{B- Inferential data analysis}

2-Group difference by ANOVA test for all histomorphometric parameter in each durations and in all area of the socket:According to Table (3), Coronal area of the socket showed highly significant difference in osteoblasts, and osteocytes at2 weeks durations, and had significantly difference in trabecular area at 4 weeks duration. On the other hand the middle area of the socket showed highly significant difference in osteocytes at2weeks durations, and had significantly difference in osteoblasts at 4weeks duration.

Table (3): Group differences by ANOVA test for histomorphometric parameter in each durations in all area of the socket

\begin{tabular}{|c|c|c|c|c|c|c|c|c|c|c|c|c|}
\hline \multirow{2}{*}{ Factors } & \multicolumn{2}{|c|}{ O B } & \multicolumn{2}{|c|}{ O C } & \multicolumn{2}{|c|}{ OCL } & \multicolumn{2}{|c|}{ T.NO } & \multicolumn{2}{|c|}{ T.AREA } & \multicolumn{2}{|c|}{ BM AREA } \\
\hline & $\mathbf{F}$ & Sig. & $\mathbf{F}$ & Sig. & $\mathbf{F}$ & Sig. & $\mathbf{F}$ & Sig. & $\mathbf{F}$ & Sig. & $\mathbf{F}$ & Sig. \\
\hline Coronal $* 2$ weeks & 11.044 & $.002 * *$ & 9.755 & $.003 * *$ & .867 & .445 & .719 & .507 & 2.015 & .176 & .253 & .780 \\
\hline Coronal*4weeks & 1.214 & .331 & 1.231 & .326 & .400 & .679 & .366 & .701 & 4.669 & $.032 *$ & .599 & .565 \\
\hline Middle*2 weeks & .961 & .410 & 13.466 & $.001 * *$ & 3.733 & .055 & .123 & .885 & ".471 & .635 & .017 & 9.983 \\
\hline Middle*4 weeks & 6.016 & $.015^{*}$ & .770 & .485 & .083 & .921 & .452 & .647 & 1.329 & .301 & .277 & .763 \\
\hline Apical*2 weeks & .538 & .597 & 2.267 & .146 & 1.778 & .211 & 2.447 & .128 & 1.039 & .384 & .764 & .487 \\
\hline Apical *4 weeks & 3.294 & .072 & .301 & .745 & .000 & 1.000 & .000 & 1.000 & 3.328 & 2.071 & 1.390 & .286 \\
\hline
\end{tabular}

2-Duration comparisons ANOVA test for each group in three socket area: Table (4) the results showed highly significant duration difference in osteoblasts and trabecular number in area of the socket. On the other hand the osteocytes showed highly significant difference of $\mathrm{C}$ group in coronal area, and in sponge group in both middle and apical area. Regarding the difference in osteoclasts, in apical area showed highly significant difference in $\mathrm{C}$ group. In the coronal area the trabecular area showed highly significant duration difference in both $\mathrm{C}$ and GS groups. While in middle area of the socket, trabecular area showed highly significant duration differences GS group. Whereas, the bone marrow space area in apical area of the sockets showed highly significant difference in both GS and in $\mathrm{S}$ group (S). 
Histological Evaluation of the Effect of Local Application of Grape Seed Oil on Healing Process of

Extracted Tooth Socket in Rabbits

Manar Abd Alrazaq Hassan

Table (4): Duration comparisons by ANOVA test for all histomorphometric parameters in each group in three socket area

\begin{tabular}{|c|c|c|c|c|c|c|c|c|c|c|c|c|}
\hline \multirow{2}{*}{ Factor } & \multicolumn{2}{|c|}{ O B } & \multicolumn{2}{|c|}{$\mathrm{OC}$} & \multicolumn{2}{|c|}{ OCL } & \multicolumn{2}{|c|}{ T.NO } & \multicolumn{2}{|c|}{ T.AREA } & \multicolumn{2}{|c|}{ BM AREA } \\
\hline & $\mathbf{F}$ & Sig. & $\mathbf{F}$ & Sig. & $\mathbf{F}$ & Sig. & $\mathbf{F}$ & Sig. & $\mathbf{F}$ & Sig. & $\mathbf{F}$ & Sig. \\
\hline Coronal ${ }^{*} \mathrm{C}$ group & 77.564 & $.000^{* * *}$ & 18.075 & $.003 * *$ & 2.500 & .153 & 15.850 & $.004 * *$ & 14.111 & $.006 * *$ & 11.295 & $.010^{*}$ \\
\hline Coronal $* S$ group & 61.337 & $.000^{* * *}$ & 7.679 & $.024 *$ & .571 & .471 & 50.205 & $.000^{* * *}$ & 7.102 & $.029^{*}$ & 6.004 & $.040^{*}$ \\
\hline Coronal* GS group & 102.961 & $.000^{* * *}$ & 1.554 & .248 & 2.909 & .126 & 59.901 & $.000 * *$ & 27.142 & $.001 * *$ & 8.457 & $.020^{*}$ \\
\hline Middle * C group & 103.846 & $.000^{* * *}$ & 5.369 & $.049 *$ & 4.235 & .074 & 61.000 & $.000 * *$ & 2.581 & .147 & 12.918 & $.007^{* * *}$ \\
\hline Middle $* \mathbf{S}$ group & 57.250 & $.000^{* * *}$ & 12.696 & $.007 * *$ & .900 & .371 & 32.400 & $.000 * *$ & 11.141 & $.010^{*}$ & 21.223 & $.002 * *$ \\
\hline Middle * GS group & 572.028 & $.000^{* * *}$ & 1.862 & .210 & 1.000 & .347 & 23.210 & .001 ** & 46.163 & $.000^{* * *}$ & 4.022 & .080 \\
\hline Apical * C group & 61.754 & $.000^{* * *}$ & .247 & .633 & 12.800 & $.007^{* *}$ & 26.955 & $.001^{* * *}$ & 8.782 & $.018 *$ & 18.554 & $.003^{* *}$ \\
\hline Apical $* \mathrm{~S}$ group & 444.851 & $.000^{* * *}$ & 28.516 & $.001^{* *}$ & 5.333 & $.050^{*}$ & 49.285 & $.000^{* *}$ & 41.612 & $.000 * *$ & 34.320 & $.000^{* * *}$ \\
\hline Apical * GS group & 170.315 & $.000^{* * *}$ & 2.503 & .152 & 2.909 & .126 & 174.050 & $.000^{* * *}$ & 22.231 & $.002 * *$ & 2.145 & .181 \\
\hline
\end{tabular}

3-Multiple group compression difference for all histomorphometric parameter in different duration and socket area:According to Table (5) LSD test for osteoblasts showed high significant difference between GS and $\mathrm{S}$ groups in coronal area at 2 weeks healing period, and between $\mathrm{C}$ group and $\mathrm{S}$ group in apical area at 4 week duration. Regarding osteocytes showed high significant difference in GS group at 2 week duration when compared with the $\mathrm{C}$ group and $\mathrm{S}$ group in coronal area of the socket, and when compared with $\mathrm{S}$ group in the middle area of the socket. LSD test for osteoclasts showed only significant difference between $\mathrm{C}$ group and GS group in middle area at 2 weeks duration.On the other hand the LSD test for trabecular number showed high significant difference between $\mathrm{C}$ with $\mathrm{S}$ group and $\mathrm{C}$ group with GS group in apical at 2 weeks durations. Whereas LSD test for trabecular area showed significant difference between $\mathrm{C}$ group and GS group in coronal area at 2 and 4weeks duration, and in middle area and apical area at 4 weeks duration. LSD test for bone marrow space area showed nonsignificant difference among all groups in all area of the socket at 2 and 4 weeks duration. 
Histological Evaluation of the Effect of Local Application of Grape Seed Oil on Healing Process of

Extracted Tooth Socket in Rabbits

Manar Abd Alrazaq Hassan

Table (5): Multiple group compression difference by LSD test for all histomorphomeric parameters in each groups and three socket area

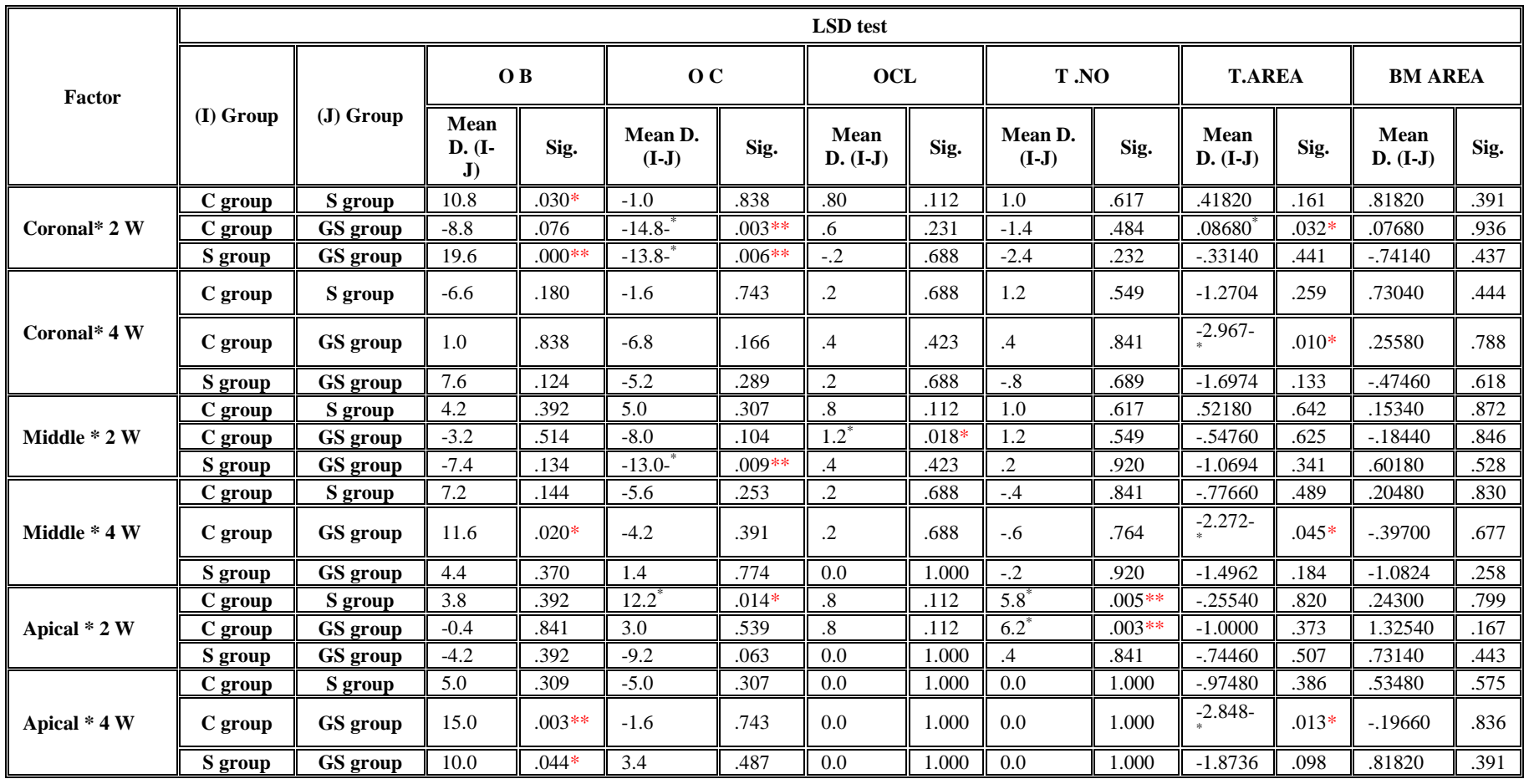

\section{Discussion}

Histological finding of the present study revealed new bone trabeculae was carried out at the end of the 2 and 4 weeks after tooth extraction for both experimental and control groups .The osteoprogenitor cells that migrate into the extraction socket differentiation results from the action of growth factors, these factors controlling bone formation and stimulate bone repair. Group of combination grape seed oil and sponge showed highly significant initiation and activation of the osteoblasts especially in the apical region of the socket than other groups This result agree with previous study done by [18].
On the other hand, the socket of control group and sponge group had delicate and less number of bone trabeculae with large size bone marrow space area when compared with grape seed oil group. This finding agreement with [19]. Increase in the number of the bone trabecules with small marrow space area in between the bone trabecule, at 2 weeks duration agree with[14], [20].

With the time at 4 weeks duration showed trabecular bone grow from the walls and base of the bone of the socket vertically toward the center of the socket, and new bone progressively replaced the connective tissue. Consuming for apposition and maturation of the bone with decreased in the number of 
Histological Evaluation of the Effect of Local Application of Grape Seed Oil on Healing Process of

Extracted Tooth Socket in Rabbits

osteoblasts and increase the number of osteocytes in all groups with different range due to entrapment of osteoblasts in their newly formed bone and lead to osteocytes formation.

More and faster osteocytes formation in bone of grape seed oil group which showed significant difference in parameters of bone architectural in different healing interval which cause faster bone building. These finding coincide with study done by [21]. Due to faster deposition and maturation of the bone the results showed significant increase in the trabecular area, with decrease in the trabecular number and bone marrow space area of the socket in grape seed oil group in comparing with sponge and control group which had less mean values. This agreement with [22],[23]. The present results can be attributed that grape seed oil directly promotes the differentiation of primary osteoblast, which is responsible for bone deposition and mineralization. The histomorphometric results of all parameters tested for micro architecture in current study records between control and experimental groups( $\mathrm{S}$ and GS groups) revealed a high mean value in experimental groups than those of control groups.

\section{Conclusions}

In conclusion grape seed oil is a bioactive herbal material that accelerates bone healing process after tooth extraction. Histological evaluation showed that grape seed oil stimulated large number of osteoblasts, osteoclast, osteocytes especially in apical portion of the socket of 2 weeks when compared with sponge and control group. Histmorphometric parameters for all groups showed highly significant difference in overall indicators of bone micro architectures include trabecular area, trabecular number, bone marrow space area.

\section{References}

[1] James K, Avery L, Pualine F AND Steele D ,2002.Oral development and histology .3rd edition; chapter 7;226-231.

[2]Nanci A., 2008. Ten Cate's Oral histology,development,structure and function .7 th edition, Mosby Elsevier,;6:111.

[3] Miclau, T., Schneider, R.A., Eames, B.F., and Helms, J.A. 2005. Common Molecular Mechanisms Regulating Fetal Bone Formation and Adult Fracture Repair. In Bone regeneration and repair: biology and clinical applications. J.R. Lieberman, and G.E. Friedlaender, editors. Totowa, NJ: Humana Press. 45-55.

[4]Sfeir, C., Ho, L., Doll, B.A., Azari, K., and Hollinger, J.O. 2005. Fracture Repair. In Bone regeneration and repair: biology and clinical applications. J.R. Lieberman, and G.E. Friedlaender, editors. Totowa, NJ: Humana Press. 21-44.

[5]Gerstenfeld, L.C., Cullinane, D.M., Barnes, G.L., Graves, D.T., and Einhorn, T.A. 2003. Fracture healing as a post-natal developmental process: molecular, spatial, and temporal aspects of its regulation. J Cell Biochem. 88:873-884.

[6]ALbayati AJ and Enaad D,2013 . Histological study and surgery effect of grape seed oil on wound healing in rabbits 
Histological Evaluation of the Effect of Local Application of Grape Seed Oil on Healing Process of

Extracted Tooth Socket in Rabbits

.International Journal of Science and Research(IJSR), Vol 4,Issue 6,959.

[7]Mureşan A. Alb C. Suciu S. Clichici S. Filip A. Login C.2010.Studies on antioxidant effects of the red grapes seed extract from Vitis Vinifera, Burgund Mare, Recaş in pregnant rats. Acta Physiologica Hungarica. 97(2), 240-6.

[8] Khanna, S.; Roy, S.; Bagchi, D.; Bagchi, M.; Sen, C. K.2001. Upregulation of oxidantinduced VEGF expression in cultured keratinocytes by a grape seed proanthocyanidin extract. Free Radic. Biol.Med. 31:38-42.

[9] Joshi, S.S., Kuszynski, C.A., Bagchi, M., Bagchi, D. 2000, Chemopreventive effects of grape seed proanthocyanidin extract on Chang liver cells. Toxicology, 155, 83-90. [10]Bruyne, T., Pieters, L., Deelstra, H., Vlietinck, A.1999. Condensed vegetable tannins: Biodiversity in structure and biological activities. Biochemical Systematics and Ecology. 27:445-459.

[11]Kennedy, J. A., Waterhouse, A. L. 2000. Analysis of pigmented high-molecularmass grape phenolics using ion-pair, normalphase high-performance liquid chromatography. Journal of Chromatography A. 86:25-34.

[12]Bouhamidi, R., Prevost V., Nouvelot, A.1998. High protection by grape seed proanthocyanidins (GSPC) of polyunsaturated fatty acids against UV-C induced peroxidation. Plant Biology and Pathology. 321:31-38.
[13]Johnson S. Barton , 2017. In Pharmacology and Therapeutics for Dentistry (Seventh Edition).

[14]Radhi I.H., 2014.Evaluation The Effect of Hyaluronic Acid on Healing Process of Intrabony Defect in Rabbits (Histomorphometrical and Immunohistochemical studies). MSc thesis, Oral diagnosis,College of Dentistry/ University of Baghdad.

[15]Viera Andreai A ,Carlos Eduardo Repeke,Ferreira Junior S DebB , Colavite PM, Claudia Cristins Biguetti,Rodrigo Cardoso Oliveira, Gerson Francisco DE Assis, Rumio Taga,Ana P. F. Trombne AND Gustavo Garlet, 2015. Intramembranous Bone Healing Process Subsequent to Tooth Extraction in Mice: Micro-Computed Tomography, Histomorphometric and Molecular Characterization; PLoS ONE 10(5):e0128021,

DOI: 10.1371/journal.pone.0128021.

[16]Xue LY., Hu N, Song YM, Zou SM, Shou JZ, Qian LX, Ren LQ, Lin DM, Tong T, He ZG, Zhan QM, Taylor PR, LU N., 2006. Tissue microarray analysis reveals a tight correlation between protein expression pattern and progression of esophageal squamous cell carcinoma. BMC Cancer; 6:296.

[17]Neamah A.D. 2013. The Role of Vege and BMP7 in Bone Healing After Topical or Systemic Fluoride Application (Experimental Study in Rats).Master thesis , Baghdad University College of Dentistry;10,11.

[18] Devlin., 2000. Early bone healing events following rat molar tooth extraction. Cells 
Tissues Organs;(167):33-37.

[19]Sanz EM., Ossipov DA., Hilborn J., Larsson S., Jonsson KB., and Varghese P.P., 2011. Bone reservoir injectable hyalonic acde hydrogel for minimal invasive bone augmentation. J. Conteol. Release; 152:233241.

[20]Phipps K., 1995. Fluoride and bone health. J Public Health Dent. Winter; 55(1):53-6.

[21]Al-Molla B., Saeed S., and AlSundokt.,2010. The effect of iragi propolis on the artificial bony defects on the rabbits mandible. Kufa med; no.1:6: 829-839.

[22]Depprich R., Zipprich H., Ommerborn M., Naujoks C., Wiesmann H., Kiattavorncharoen S., Lauer H., Meyer U., Kubler N., and Handschel J., 2008. Osseointegration of zirconia implants compared with titanium: an in vivo stud. Head and Face Medicine ;4:30.

[23]Jae-Jin Ahn and Hong-In Shin,2008.Bone tissue formation in extraction sockets from sites with advanced periodontal disease:Histomprphometric study in humans. The international journal of oral and maxillofacial implant ;Vol (23) No(6);1135. 